\title{
LA TELABASURA NUESTRA DE CADA DÍA II
}

\author{
THE JUNK TV OUR EVERY DAY II
}

David Caldevilla Domínguez: Profesor del Área de Comunicación en la Universidad Complutense de Madrid, la Universidad Europea de Madrid y Escuela Superior de Estudios de Relaciones Públicas.

david.caldevilla@ccinf.ucm.es

\section{CURRÍCULUM VITAE}

Diplomado en Magisterio por la Universidad de Zaragoza (España), licenciado en Comunicación Audiovisual por la Universidad Complutense de Madrid (España). Profesor en la Facultad de Ciencias de la Información de la Universidad Complutense. Secretario General del Fórum Internacional de Comunicación y Relaciones Públicas (España) y autor de varios artículos en revistas universitarias. Director de Operaciones de Imagométrica, s.l. y ex directivo de varias firmas españolas del ámbito de la mercadotecnia.

\section{RESUMEN}

Este artículo es una continuación de la primera parte publicada en el anterior número. Se lleva a cabo un análisis de los programas de telebasura que se emiten en las diferentes cadenas y sus presentadores. Además se expone una pequeña historia de la telebasura en España a nivel general, que empezó a instalarse en las parrillas de televisión en los años 90 a través de algunos reality shows, que nutrían la curiosidad morbosa de los espectadores mostrando las miserias de ciudadanos anónimos. 


\title{
PALABRAS CLAVE
}

Telebasura - Programas - Canales - Presentador

\begin{abstract}
This article is a continuation of the first part published in the last issue. Carried out an analysis of trash TV programs that are broadcast on different channels and its presenters. It also presents a brief history of trash TV in Spain at a general level, which began to settle in the grill TV in the 90's through some reality shows, that nourished the morbid curiosity of the audience showing the miseries of ordinary citizens.
\end{abstract}

\section{KEY WORDS}

Junk tv - Programs - Channels - Presenter

\section{ÍNDICE}

1. Introducción

2. Programas destacados de telebasura

2.1. Programas de televisión basura de TVE

2.2. Programas de televisión basura de Telemadrid

2.3. Programas de televisión basura de Telecinco

2.4. Programas de televisión basura de Antena 3

2.5. Programas de televisión basura de Canal 7

3. Antecedentes 
3.1. Historia de la telebasura en España

TEXTO:

\section{Introducción}

En esta segunda entrega, repasaremos los programas que merecen el honor de ser considerados como telebasura. Bien es cierto que algunos de ellos pueden ser considerados como programas de cierto nivel artístico (Operación Triunfo poseía el germen de un programa musical de nivel), pero su planteamiento formal los convierte en proveedores de carnaza fácil las más de las veces y por ello han sido incluidos en esta Galería de la Fama de la Telebasura Española.

\section{Programas destacados de telebasura}

\subsection{Programas de televisión basura de TVE}

\section{GENTE}

Algo de historia:

El programa Gente se emite de lunes a viernes, de 20.00 a 21.00 horas, horario peninsular, por la Primera de TVE. En sus inicios comenzó a emitirse con el nombre de Gente de primera en octubre de 1993, hasta abril de 1994. Tras un período sin estar presente en la programación de esta cadena, regresó a la parrilla en octubre de 
1995, con el nombre de Gente en cartelera. A partir de enero de 1996 pasó a llamarse Gente, tal como lo conocemos hoy.

Programa y profesionales:

Se trata de un magacín dividido en dos partes. La primera parte se ocupa de la crónica de sucesos y otros temas de carácter social. La presentadora encargada de comentarnos los acontecimientos pertenecientes a este espacio es Pepa Bueno, que es, además, la subdirectora del mismo.

La crónica de sucesos muestra especial interés en ofrecer con el mayor rigor periodístico y humano posible toda la información que se facilita al espectador. Se trata de conseguir mostrar a los verdaderos protagonistas de las historias que se ofrecen en el programa y que sean ellos quienes lo cuenten desde su propia perspectiva.

La segunda parte del programa está dedicada a la crónica social, emitida entre las 20.30 y las 21.00 horas. Sonia Ferrer se encarga de presentárnosla.

En cuanto a la crónica social, el programa intenta en todo momento facilitar y dar a conocer informaciones de interés sobre personajes que se han ganado la notoriedad pública gracias a su actividad profesional. No se trata de ser un simple cotilleo sino de facilitar la presencia en las pantallas de TVE a aquellas personas que realmente tengan algo interesante que contar.

La moda, por supuesto tiene un protagonismo especial en Gente. Nos proporciona información detallada sobre los deferentes desfiles que tienen lugar en España y en el resto del mundo. Alicia Santolaya es la directora de este programa. 
Aspectos técnicos y de producción:

Gente tiene una producción de noticias interna, luego no lleva a cabo ningún tipo de coproducción con nadie.

Las fuentes de información que utiliza para su elaboración y producción son las agencias de noticias con servicio de teletipos; también se sirven de free-lance distribuidos en aquellas zonas en donde se produce o surge la noticia.

Entre las agencias de las que se sirven para elaborar el programa se encuentran: la Agencia EFE y Europa Press.

También en ocasiones tiene lugar intercambio de imágenes entre programas de la misma cadena o de otras.

Al ser un programa diario (se emite de lunes a viernes) la preparación del programa es de un día o jornada de trabajo completa de trabajo.

El programa Gente se emite en directo, por tanto no hay grabación; el tiempo de emisión es de una hora.

Algunas Profesionales que hacen gente:

Alicia Fernández Santolaya nació el 14 de noviembre de 1961 en Villamediana, La Rioja. Es licenciada en Ciencias de la Información, rama Periodismo, por la Universidad Autónoma de Barcelona. Empezó a trabajar en el mundo de la información en 1982, en el periódico La Rioja. Posteriormente se incorporó a El Correo Español, el Pueblo Vasco, donde estuvo hasta 1983. 
En TVE empezó en 1985, en la sección de Sociedad de los Telediarios, donde estuvo durante tres años. Después trabajo en el programa En Familia, con Iñaki Gabilondo. Tras esta experiencia se incorporó al programa Espiral detrás de la noticia, dirigido y presentado por José Antonio Martínez Soler. Más tarde, entre 1991 y 1994, se incorporó a Días de cine, hasta que se hizo cargo de la subdirección de Cartelera y Cartelera TVE.

Desde 1996 es directora de Gente, programa de TVE líder indiscutible en su franja horaria. Se trata de un programa de sociedad y actualidad con una fórmula informativa.

Pepa Bueno es periodista y comenzó su labor como redactora en los Servicios Informativos de RNE-Extremadura. Fue Jefa de Informativos de RNE-Aragón y colaboradora de Diario 16 en esa región. Además, ha sido Jefa de Informativos de Radio 4 y RNE-Madrid.

En 1991 pasa a TVE como Jefa de Informativos del Centro Territorial de TVEAndalucía, donde dirigió y presentó el informativo regional de las 14,00 horas. Durante esta etapa afrontó la cobertura de grandes acontecimientos como la Expo 92, la visita del Papa Juan Pablo II o la boda de la Infanta Doña Elena. Más tarde se hizo cargo de la dirección del Centro Territorial de TVE-Madrid y de la edición y presentación del Informativo Regional de las 20,00 horas.

Desde el verano de 1996 es subdirectora de Gente, además de presentadora de la página de sucesos del programa.

Sonia Ferrer nació en Barcelona y domina los idiomas inglés y francés. Estudió bachillerato en Francia, donde pasó las pruebas de Selectividad. También en ese país realizó estudios de danza clásica en la Escuela Rosella Hightower. Además, ha 
realizado estudios de Técnico en Empresas Turísticas y de Locución, Redacción y Presentación en Radio y Televisión.

Su experiencia profesional no se limita sólo al campo de la televisión, porque ha participado en diferentes desfiles de moda, entre los que destacan los realizados en el Salón Gaudí de Barcelona. A esto hay que añadir su experiencia como modelo fotográfica en Milán y Japón.

Su experiencia televisiva le ha permitido participar en diferentes proyectos. Ha sido co-protagonista de la serie para TVE Happy House y presentadora de Café Cosmopolitan, programa emitido a través del Canal Cosmopolitan. En la actualidad es presentadora de la sección de sociedad de Gente.

\section{OPERACIÓN TRIUNFO}

Programa musical y de entretenimiento en el que 16 jóvenes son preparados y formados por profesores y artistas en una academia; compiten en un proceso eliminatorio, para finalmente elegir al ganador que representará a España en el Festival de Eurovisión.

El proceso de elección se realiza en unas 15 galas televisivas donde el público, el jurado, los profesores y los propios concursantes hacían las labores finales de elección.

En sus primeras ediciones el programa batió récords de audiencia, venta de discos, vídeos, llamadas telefónicas, mensajes de correo electrónico, de solicitudes de castings, de esperas de público para asistir a las galas, y de repercusión tanto en los medios de comunicación nacionales e internacionales. 
La combinación de TVE y Telefónica- Admira, ha terminado por ser un binomio tremendamente eficaz. Idea, producción y emisión se juntaron con viento a favor. OPERACIÓN TRIUNFO es una producción del gigante holandés ENDEMOL.

En paralelo, una de las más grandes empresas españolas, El Corte Inglés, junto con Sony Music, abrazaron el éxito gustosamente sirviendo de canal de distribución comercial. Desde que comenzó a cristalizarse el triunfo, éstas y otras empresas se sumaron a esta estela de ganancias no sólo económicas.

Televisión en abierto (TVE), televisión de pago (Canal Satélite Digital), Teléfono (Telefónica- Moviestar), Internet (Portalmix), y una cadena de comercios (El Corte Inglés), han confluido estratégicamente potenciándose unos a otros con el fin de hacer llegar la oferta-producto a una demanda creciente. Con OPERACIÓN TRIUNFO se ha dado luz a un nuevo sujeto social, mitad audiencia, mitad consumidor. Un nuevo sujeto que podría denominarse consumidor mediático, y que necesita un nuevo tratamiento, y nuevas formas de abordaje comercial.

Este programa lleva ya tres ediciones, la primera de ellas cosechó gran éxito, con altos índices de audiencia, la segunda edición tuvo algo menos de notoriedad, quizás porque ya era algo conocido, y la tercera, que hasta finales del año 2003 podíamos verla en TVE, ha sido un rotundo fracaso, tal ha sido que han tenido que acortar el tiempo de emisión previsto y acabar antes de lo estipulado.

\section{CORAZÓN CORAZÓN}

Es el programa pionero de la crónica social en televisión que, cada fin de semana, se emite, a partir de las 14.30 horas, bajo la dirección y presentación de Cristina García Ramos, en La Primera y Canal Internacional de TVE. Ofrece la última hora de las noticias internacionales y nacionales de su género y ha cumplido una década de emisión ininterrumpida en la programación de TVE. 
A lo largo de estos 10 años de emisión, CORAZÓN CORAZÓN ha ofrecido un total de 8.000 reportajes y entrevistas, en 900 programas, repartidos en casi 500 horas de emisión, durante las cuales han pasado por el programa los rostros más conocidos de la crónica social.

Para conmemorar este décimo aniversario, CORAZÓN CORAZÓN viene emitiendo en estos meses entrevistas con los principales personajes de la crónica social que han pasado por el programa a lo largo de su historia.

CORAZÓN CORAZÓN se ha convertido, en estos 10 años, en uno de los veteranos de TVE, y en pionero entre los dedicados al mundo de la sociedad, dando pie para que otras cadenas de televisión, con mayor o menor suerte, produzcan espacios de este tipo.

El programa de TVE siempre ha tenido unas señas de identidad propias y una fórmula consolidada, en la que prevalece el rigor de la noticia y una cuidada selección de temas y personajes que le han llevado a convertirse en el espacio más seguido por la audiencia en su género.

Cada semana, CORAZÓN CORAZÓN ofrece una media de 50 minutos de emisión y 18 temas, reportajes y entrevistas, en los que se recogen la última hora de lo más importante de la vida social, siendo testigo directo en todos los actos de especial relevancia y pionero en informar sobre moda en televisión.

UN CLÁSICO DEL GÉNERO - secciones

A lo largo de estos diez años CORAZÓN CORAZÓN ha contado con secciones habituales que le han llevado a convertirse en un clásico de este género. Un género 
difícil, polémico, agresivo en algunas ocasiones, susceptible en muchas, que necesita de una gran sensibilidad y tacto informativo lejos del "amarillismo" y la falta de calidad. El programa trata siempre de transmitir el lado profesional del personaje, combinado con la proyección humana y familiar del mismo.

Además, el hecho que CORAZÓN CORAZÓN se emita el fin de semana, en ediciones de sábado y domingo, y sobre todo se emita en directo, ha permitido que en el programa prime la actualidad y sea el primero en informar de los grandes acontecimientos sociales del momento como bodas, bautizos, fiestas y tantos otros temas que componen la crónica social.

\section{EL PRIMERO CON LA MODA:}

CORAZÓN CORAZÓN también ha sido el primer programa que ha dedicado una sección al mundo de la Moda, con la seriedad y profesionalidad que esta actividad merece. Ya es habitual la presencia de CORAZÓN CORAZÓN en las grandes pasarelas de París, Milán, Nueva York, Londres, Madrid y Barcelona, desde donde se siguen las últimas novedades de los diseñadores nacionales e internacionales.

Las grandes firmas, también, abren las puertas de sus casas y talleres a las cámaras del programa, permitiendo conocer el lado más personal de su trabajo.

El programa informa también del fenómeno social de las top model, tratadas con el glamour y rigor informativo que requieren sus noticias.

Además, en las páginas televisivas de CORAZÓN CORAZÓN se pueden encontrar también las estrellas nacionales e internacionales del cine y del teatro.

Jesús María Montes-Fernández Fernández uno de los redactores más veteranos de este espacio, que permanece en el programa desde sus inicios como responsable de la 
Página de Moda, recibió el año pasado el Premio al Mejor Periodista de Moda de Televisión, en nuestro país, en la primera entrega de los Premios "Moët Chandon a la Difusión de la Moda" y ha conseguido, junto al equipo del programa, incluir a CORAZÓN CORAZÓN en la primera Exposición sobre Moda Española que se celebra en el Museo Reina Sofía de Madrid desde el próximo 18 de Junio hasta el 28 de Setiembre, de la que es uno de los comisarios responsables de contenidos.

\subsection{Programas de televisión basura de Telemadrid}

\section{MAMMA MÍA}

Tipología: programa de crónica "rosa".

Presentadores: Víctor Sandoval y Patricia Pérez.

Emisión actual: lunes a jueves de 21:30 a 21:55.

Director: Juan Luis Alonso.

Producción: programa de producción propia interna, centrado en la actualidad de los famosos con tono desenfadado. Populares temas de karaoke.

Trayectoria profesional de los presentadores:

Víctor Sandoval: nació el 16 de enero de 1967 en Madrid. De carácter inquieto e hiperactivo. Su primera aparición en televisión fue con 9 años, en el programa de Torrebruno, llamado la "Guagua", en TVE. Desde ese momento empezó a cantar en karaokes aplaudido por su abuela en todo momento, pero la influencia de sus padres, le hizo optar por los estudios de Periodismo; al mismo tiempo lo 
compaginaba con sus estudios de Arte Dramático y Foniatría. Tras hacer figuraciones en diversas películas, como "Sangre y Arena" con Sharon Stone, y protagonizar un gran número de cortometrajes, dirigidos por Alfonso Albacete, debuta en 1985 en el teatro Reina Victoria de Madrid, con la obra "Hermano hombre", junto a Juan Carlos Naya. También debuta como cantante en 1990. Su primer disco, "Frío control" lo grabó en 1993; a raíz del cual, comenzó su promoción como cantante por diversas cadenas de televisión, siendo fichado por Telecinco para el programa "¿De qué parte estás?". Éste, era dirigido y presentado por José María Íñigo, y Víctor se dedicaba a opinar sobre temas de actualidad, dejando a un lado su carrera como cantante y empezando la de comunicador.

Con el programa, Víctor, adquirió mucha popularidad y empezó a desarrollar diferentes actividades como Relaciones Públicas hasta 1998, cuando es contratado por una de las más importantes productoras de España para trabajar como periodista, junto a Ana rosa Quintana, en el magacine televisivo "Sabor a ti", de Antena 3, donde realizó corresponsalías en Londres, Milán, Cuba... Así como reportajes diarios de la crónica social.

En el verano de 1999 es fichado por Telemadrid para presentar junto a Francine Gálvez, el magacine "Mamma Mía", colocándose líder de audiencia. Posteriormente pasa a presentar hasta el siguiente verano, en el que volvería "Mamma Mía", un programa semanal en Prime Time de tres horas de duración llamado "Macumba Te Ve", en el que tuvo la oportunidad de desarrollar su faceta de actor. Terminado El verano, Pilar Soto sustituyó a Francine y el programa pasó a emitirse de lunes a viernes. Al mismo tiempo, Víctor es contratado para el programa de la cadena Cope de Radio "La Mañana" dirigido y presentado por Luis Herrero. También participó en "Al tran trán", donde da un repaso a la crónica social. 
También es contratado por $\mathrm{M}^{\mathrm{a}}$ Teresa Campos para su magacine "Día a Día", en Telecinco, en la sección "El corrillo". Telemadrid también le dio la oportunidad de retransmitir las campanadas de 2001, junto a Pilar Soto y las del año 2002 junto a Patricia Pérez (su actual compañera en "Mamma Mía"), acontecimiento que se repitió en 2003. Además, aparece en un programa llamado Xanadú.

Actualmente Víctor y Patricia presentan en Telemadrid, en directo, el programa "Mamma Mía", que el 16 de enero de 2003 fue distinguido con el premio al programa de producción nacional de mayor audiencia por GECA.

Patricia Pérez: Esta gallega de 29 años dio sus primeros pasos en el programa "Luar" de la TVG, después de que un fotógrafo se colara en su vida, repartida entre clases de conservatorio (quería ser profesora de música), y funciones teatrales escolares; además, una agencia se fijó en ella.

Patricia se dio a conocer a nivel nacional en el programa "El Gran Juego de la Oca", de Antena 3.

Tras dos años y medio en Argentina, donde trabajó como presentadora de televisión y actriz, regresó a la pequeña pantalla de su Galicia natal. Hasta que en el año 2000 presentó el programa "Emisión Imposible" en Telecinco.

Actualmente presenta junto a Víctor Sandoval El programa "Mamma Mía" en Telemadrid.

\section{CON T DE TARDE}

Tipología: Magacine de actualidad de la prensa del corazón. 
Presentadora: Terelu Campos.

Colaboradores: José Rodríguez Sieiro, Pepa Jiménez, Enrique del Pozo, Enrique Miguel Rodríguez, Stela Goñi, Carlos Pérez Gimeno, Michelle Tauzia, Paloma Navarrete, Rosa Villacastín, Ángel Antonio Herrera, Javier Lazareno, Tico Medina, Marian Conde y Arturo Tejerina.

Temas: crónica "rosa", tertulias sobre sexo o crónica negra, debates sobre nutrición o comida naturista, decoración del hogar, desfiles de moda y horóscopos.

Emisión actual: lunes a viernes, de 16:00 a 18:00 horas. Con interrupción en los mese de verano.

Directora: Begoña González.

Producción: programa de producción propia interna. Magacine centrado en la prensa "rosa".

Derechos: Europroducciones y Telemadrid.

Trayectoria de Terelu Campos:

En 1984 comenzó a trabajar en Radio Cadena Española, en los programas "Apueste por una" y "Te vas a enterar". En 1987 dirigió y presentó "Las mañanas de la Cadena Rato" en Radio Torcal de Málaga. Se incorporó a la televisión en 1988, primero al programa de Jesús Hermida "Por la Mañana", y luego, junto a Ma Teresa Campos, en "Esta es su casa". Terelu Campos pasó por muchos programas y fue productora musical del programa "Pasa la vida" en TVE y Antena 3. Después continuó 
colaborando en el programa "Día a Día", que su madre presenta en Telecinco. Actualmente "Con T de Tarde" ha sido retirado de la programación.

ESTRATEGIAS DEL PROGRAMA: las tertulias del programa se desarrollan en un set con una mesa redonda a la que se sientan presentadores fijos, y ante la presencia de un público "popular" en el plató (de mayoría femenina y edad enmarcada por referencia a espacios reconocibles de la sociedad doméstica: la mesa camilla de la sobremesa. Se trata de un escenario que corresponde a una situación convencional estereotipada: la reunión familiar de sobremesa.

El programa incluye reportajes que se hacen objeto de comentario. El género puede contextualizarse en esa cultura televisual que, según palabras de Mehl (1996), "trata de restaurar la conversación interrumpida", y también en ese proceso de privatización del "espacio público" que supone una complementaria "publicitaria del espacio privado".

En la neotelevisión, que es una televisión de la interpersonalidad, donde la atracción al espectáculo se renueva mediante el imaginario del dialogo (Ehrenberg: 1993), las interacciones entre individuos y experiencias suplantan a aquellas representaciones de la sociedad en las que "las relaciones de influencia, poder y clase ocupaban el proscenio" (Mehl, 1996: 231). Las observaciones de esta autora se refieren al reality show, pero son en general aplicables al conjunto de los géneros conversaciones y, por ende, a la conversación rosa. Incluso se percibe una complementariedad simétrica: en el reality show los "profanos" se profesionalizan ante las cámaras; en la tertulia rosa, los profesionales adoptan el papel de los espectadores profanos, "abandonando en gran parte ese distanciamiento que les caracterizaba como representantes de una institución a la que se atribuían importantes funciones de socialización, para (...) implicarse en la conversación, utilizar el mismo lenguaje que sus invitados, entrar en 
contacto físico con ellos, bromear sin demasiada agudeza, hacer como que se equivocan o mostrar los propios sentimientos y opiniones" (Castañares, 1995: 115).

Volver al principio del epígrafe Volver al principio del artículo Volver al principio

\subsection{Programas de televisión basura de Telecinco}

\section{CRÓNICAS MARCIANAS}

Presentador/director: Xavier Sardá

Dirección: Joan Ramón Mainat

Guión: Javier Vidal y Joan Tresseras

Redacción: Jorge Pazos, Albert Barba, Mercedes Garro y Sergi Torres

Productora: Gestmusic Endemol

Derechos: Gestmusic Endemol y Telecinco

Ironía, acidez, dinamismo, trasgresión, sorpresas e, incluso, polémica. "Crónicas Marcianas" mantiene las señas de identidad que le han convertido en la apuesta más estable y consolidada de la franja del late night de la televisión de nuestro país. El programa que dirige y presenta Javier Sardá está ya asociado a la cita diaria de la audiencia noctámbula que sigue un programa que mezcla periodismo y espectáculo, actualidad y humor, rigor y provocación. El reto de "Crónicas Marcianas" es seguir siendo el referente del público más trasnochador que le ha llevado a ostentar el título de líder indiscutible en su franja horaria. 
El programa mantiene la línea del entretenimiento con un toque particular de humor, un tono satírico y una visión siempre crítica con la vida y la actualidad. Para ello, Sardá cuenta con sus marcianos de lujo: Boris Izaguirre (sección de "análisis social"), Carlos Latre (imitador de los personajes más peculiares de la vida social), Javier Cárdenas (se encarga de entrevistas y hace un repaso de las cadenas de televisión), Javier Deltell (como reportero callejero) y Rocío Madrid (ofrece reportajes y vídeos).

La mesa del corazón cuenta con los ácidos y peculiares comentarios de unos tertulianos: Coto Matamoros, Carmen Hornillos, Mari Cielo Pajares, Begoña Ameztoy... que ofrecerán la actualidad más candente de los protagonistas del papel couché.

Las noches marcianas también se hacen eco de la $5^{\text {a }}$ edición de Gran Hermano. Para ello, y como cada año, Crónicas traslada a su audiencia todo lo que sucede en la casa de Guadalix de la Sierra, a través de las opiniones de los ex concursantes: Marta López, Jorge Berrocal, Kiko, Raquel... y demás colaboradores: Silvia Fominaya...

Hay días especiales, días en los que se tocan unos temas concretos presentados por especialistas.

El debate: Algunos martes llegan hasta Crónicas los debates de actualidad. El Papa, el Prestige o la postura ainti-condón de la Iglesia son algunos de los temas que se han tratado hasta el momento. Entre los tertulianos habituales, la ex-parlamentaria de ERC Pilar Rahola, el filósofo Gustavo Bueno, la abogada Gemma Pascual...

ü Concursos para la tercera edad presentado por José Carlos Ortega que graba entrevistas y miniconcursos, protagonizados por ancianos.

ü Monólogos de Enrique Ponti 
ü Sucesos presentado por Paco Pérez Abellán que comenta los misterios, crímenes y asuntos sin resolver durante las noches marcianas.

ü Internet bajo el ciberguionista Xavier Vidal.

La nota musical sigue siendo una constante del programa, se han ofrecido cerca de 900 actuaciones de diferente corte, y en el programa se han podido escuchar más de 48.000 canciones y ráfagas musicales.

Además, el programa ha servido como plataforma de lanzamiento hacia el éxito a muchos profesionales que han formado parte del variado y atrevido grupo de colaboradores de Sardá. Ellos han contribuido a que el show sea el programa nocturno preferido de un público mayoritariamente joven (entre 13 y 34 años) de clase media alta.

\section{PECADO ORIGINAL}

Clasificación: programa

Género: corazón

Reparto: no hay conductor

Productora: Atlas

Derechos: Atlas y Telecinco 
Programa diario, sin presentador, que persigue a los famosos día y noche para servirle en bandeja los mejores reportajes de la crónica rosa y, además, muestra la cara más divertida de la televisión. Sus señas de identidad son un guión vivo, con marcado sentido del humor. La vis cómica de los famosos, la opinión de la calle, los rumores que circulan en las redacciones y los gags de Internet, entre otros aspectos, componen las diversas secciones: la sección de "zapping" sigue con atención los programas de crónica rosa de diversos canales autonómicos y locales; los rumores y noticias pendientes de confirmación que corren en las redacciones tienen cabida en "Bajo sospecha", espacio que indica con grafismo el porcentaje de credibilidad. El programa pulsa en el espacio "La gente opina", el punto de vista de la gente de la calle recogido en lugares como bares, peluquerías y mercados.

\section{DÍA A DÍA}

Estreno: septiembre 1996

Clasificación: magacín

Género/ formato: actualidad

Director: $\mathrm{M}^{\mathrm{a}}$ Teresa Campos

Productora: Grupo Europroducciones

Presentadora: $\mathrm{M}^{\mathrm{a}}$ Teresa Campos

Derechos: Telecinco y Europroducciones 
Magacine matutino que ofrece los mejores debates, tertulias, entrevistas, concursos, actuaciones musicales al hilo de la más puntual actualidad, contando para ello con un amplio plantel de prestigiosos colaboradores. El programa conjuga información y entretenimiento al ritmo de un directo de dos horas y media, sin olvidar las novedades, por lo que incorpora nuevas secciones y colaboradores.

Por ejemplo, todos los martes, María Teresa Campos tiene que aguantar las impertinencias y el humor visceral de una colaboradora de lujo muy especial: "la script", encarnada por Terelu Campos. Otra sección relevante a lo largo del programa es "El corrillo" en el que se habla de lo último acontecido en Gran Hermano que cuenta con concursantes de pasadas ediciones y con otros colaboradores del corazón. La última actualidad política y social es analizada a diario por el amplio plantel de periodistas habituales en sus tertulias y debates. El interés social y la investigación periodística son una parte fundamental en el programa sin olvidar el corazón como nota divertida.

Además, "Día a Día", siempre ha estado abierto a la participación de los telespectadores tanto en los concursos como en otros apartados del programa donde su opinión o testimonio son muy importantes.

El programa, tras siete temporadas en la parrilla, es líder indiscutible en su franja horaria.

\section{GRAN HERMANO 2000}

Estreno: 23 de abril del 2000

Clasificación: concurso 
Género/ formato: reality show

Director: Ricardo Ontiveros

Guionista: idea original de la productora holandesa Endemol de John de Mol

Productora: Zeppelín TV

Presentadora: Mercedes Milá

Gran Hermano ha marcado claramente un antes y un después en la televisión española. Representa claramente la nueva tendencia que se ha impuesto en todo el mundo, el realismo televisivo, que consiste en mostrar como espectáculo las situaciones habituales de personas "normales" que podrían ser como un familiar o un vecino nuestro.

En un principio se presentó como un experimento sociológico que consistía en observar de forma permanente la vida de diez personas anónimas dentro de una casa. Para que esto fuese posible se colocaron varias cámaras repartidas por toda la casa. Los jóvenes que participaron en el concurso pasaron a ser conocidos en todo el país.

La vida dentro de la casa se podía seguir las 24 horas a través de las plataformas Quiero y Vía Digital. Además, Tele5 ofrecía resúmenes diarios y programas especiales.

La primera edición del programa tuvo un share del 52,1\% y un promedio de espectadores de 8.286.000. Esto nos muestra que fue muy bien acogido por la audiencia, pero también fue muy criticado por algunos sectores. 
Estreno: 23 de abril del 2000

Última emisión: 21 de julio del 2000

Resúmenes diarios en prime time

Programa especial: los miércoles 10pm

Programa especial resumen: los domingos 10pm

Presentado por Mercedes Milá y Fernando Acaso

Concursantes: Ismael, Ania, Iván, Israel, Nacho, Vanesa, $\mathrm{M}^{\mathrm{a}}$ José, Jorge, Koldo, Silvia, Marina, Mónica, Íñigo y Mabel

PREMIOS:

- TP de Oro 2000 al Programa revelación del año

- Premio al programa más visto de la temporada, otorgado por el Gabinete de Estudios de la Comunicación Audiovisual (GECA).

- Ha sido catalogado como uno de los 10 mejores programas del milenio por Corporación Multimedia, empresa especializada en el análisis de audiencias, en su un informe general de audiencias en el año 2000.

\section{GRAN HERMANO 2003}

En esta quinta edición podemos seguir la evolución del concurso a través de los programas que emite Tele5:

\section{DEBATE}

Clasificación: concurso 
Género/ formato: reality show

Director: Ricardo Ontiveros

Guionista: idea original de la productora holandesa Endemol de John de Mol Productora: Zeppelín TV

Presentador: Jesús Vázquez

Es una recopilación de los momentos más interesantes de la semana, comentados por el presentador y los invitados al debate. Se emite los domingos de 21:30 a 00:15 y lo presenta Jesús Vázquez.

\section{$\underline{\text { GALA }}$}

Cada jueves de 22:00 a 1:00 Mercedes Milá presenta el programa estrella del reality show. Los concursantes nominan o son expulsados de la casa. Además incluye entrevistas a familiares o amigos de los concursantes. Ellos comentan lo sucedido en la casa en los últimos días.

\section{AQUÍ HAY TOMATE}

Estreno: 24 de marzo de 2003

Clasificación: magacín

Género/ formato: actualidad, humor 
Director: Adrián Madrid

Productora: Atlas

Presentador: Jorge Javier Vázquez y Carmen Alcayde

Derechos: Telecinco y Atlas

Este Magacine, estrenado el 24 de marzo de 2003, analiza con humor la actualidad social del país. Se emite de lunes a viernes de 15:30 a 16:30.

En Aquí hay tomate se da mucha importancia a los 12 reporteros que están repartidos por toda España y se encargan de la persecución de los diferentes famosos.

En un principio, la parte de "Tomate social" se dividió en distintas secciones, entre ellas:

- La exclusiva: una noticia nueva que no ha sido aun difundida.

- La lata: el reto consiste en entregar a algún famoso una lata con el logo del programa.

- El notición: un análisis de la noticia más increíble, aunque cierta.

- Agenda Real: repaso a las actividades de la Familia Real.

- Píldoras en la calle: pregunta formulada a los viandantes. 
- Parodia de SMS: frases que aparecen como enviadas por famosos desde su móvil a lo largo del programa.

Alrededor del 18\% de share y 2.000 .000 espectadores

\section{$\underline{\text { A TU LADO }}$}

Estreno: 11 de febrero de 2002

Clasificación: magacín

Género/ formato: entretenimiento

Director:

Guionista:

Productora: Martingala TV

Presentador: Emma García y Félix Álvarez

Derechos: Telecinco y Martingala

Este magacine, presentado por Emma García y Félix Álvarez, se emite cada tarde de 17:30 a 20:30.

En un principio fue un talk-show que duraba una hora y media. En abril de 2002 aumentó sus contenidos y desde mayo de ese mismo año dura tres horas. 
Tiene contenidos variados: debate sobre lo ocurrido en Gran Hermano, noticias del corazón, testimonios etc.

Además de los presentadores, en este programa participan comentaristas de Gran Hermano, colaboradores del corazón y humoristas.

\subsection{Programas de televisión basura de Antena 3}

\section{COMO LA VIDA}

De lunes a viernes, Alicia Senovilla tiene una cita con todos vosotros a las 10:00 horas. Alicia Senovilla repasa cada día en "Como la vida" las noticias más destacadas de la prensa "rosa" con el humor como eje fundamental.

Karmele Marchante, Ernesto Neyra, Antonio Sánchez Casado, Gustavo González y Carlos Ferrando, entre otros colaboradores, analizan cada día las noticias más relevantes sobre los personajes famosos desde un punto de vista alegre y dinámico...

Además, queremos acercarnos a los problemas diarios, a las experiencias vitales y personales, con los testimonios de gente como tú.

De lunes a viernes, a partir de las 10 de la mañana, te mantendrá informado de toda la actualidad del mundo del corazón.

NOTA DE VA: Esta presentación proviene del propio programa.

\section{¿DÓNDE ESTÁS CORAZÓN?}


Los viernes por la noche, Jaime Cantizano te espera con los protagonistas de la actualidad y el repaso de la "semana del corazón".

¿Dónde estás corazón? es el programa semanal de Antena 3 en el que se dan cita los protagonistas de la crónica social para someterse a un interesante "careo" con algunos de los más brillantes periodistas de nuestro país.

Cada viernes, en directo, polémica, el debate y el testimonio son los protagonistas. Todas las noticias, todos los rostros, todas las opiniones están reflejadas en este espacio ameno y al mismo tiempo incisivo.

Con colaboradores como Chelo García-Cortés, Antonio Montero, Maria Patiño, Gustavo González y Gema López, este espacio se ha convertido ya en un referente de la vida social española.

Dentro de este espacio, hay una novedad, ¿Dónde estás corazón? estrena "Que trabaje Rita", una sección de humor interpretada por unos traviesos muñecos que parodiarán a los personajes más conocidos del panorama social.

NOTA DE VA: Esta presentación proviene del propio programa.

\section{$\underline{\text { SABOR A TI }}$}

De lunes a viernes Ana Rosa te espera a las 16:45 horas en Antena 3. Todas las tardes en Sabor a ti, Ana Rosa Quintana te da a conocer todas las novedades de la crónica rosa. Además, la actualidad, la tertulia y los testimonios son partes imprescindibles de este espacio. Si quieres estar informado de todo lo que ocurre en el mundo del corazón, no puedes perderte esta cita diaria. 
Para ello, Ana Rosa cuenta con unos colaboradores de lujo, entre lo que se encuentran nombres del periodismo social como Chelo García Cortés, Miguel Temprano, César Heinrich y muchos más.

NOTA DE VA: Esta presentación proviene del propio programa.

\section{EL DIARIO DE PATRICIA}

Bilbaína de 35 años, es una de las figuras más populares de la televisión autonómica ETB. La periodista inició precozmente su carrera ante los micrófonos y, con tan sólo 17 años, comenzó a desarrollar su andadura profesional en los 40 Principales. Continuó presentando diferentes programas en Radio Euskadi hasta que se incorporó a Euskal Telebista para presentar el programa de debates "Toma y Daca".

Más tarde pasó a presentar "Al cabo de la calle" y luego compaginó "Ésta es mi gente" y el concurso "Números rojos".

Su trayectoria profesional le ha hecho merecedora de numerosos premios, entre los cuales destaca el TP de Oro 2002 al mejor magazine. Este verano presentó "Menta y Chocolate" y ahora vuelve con "El diario de Patricia"

\section{$\underline{\text { AHORA }}$}

"AHORA" un programa con reportajes y noticias con un tono ligero y cercano al espectador. Un espacio en la que el televidente conocerá toda la actualidad rosa de forma divertida y amena. 
Todas las noticias del corazón mezcladas en un divertidísimo cóctel y servidas por la guapa Cristina Saavedra.

Todo esto lo podemos encontrar cada semana en Ahora, el programa que emite cada sábado en Antena 3 de 19.55 a 21.00 h.

Cristina Saavedra nació en La Coruña en 1975. Licenciada en periodismo por la Facultad de Comunicación de la Universidad de Santiago de Compostela, ha desarrollado toda su trayectoria profesional en TVG, la televisión autonómica gallega, hasta su incorporación a Antena 3.

En 1997, se incorporó a la redacción de informativos de TVG y en 1998 trabajó en la delegación en La Coruña como redactora y presentadora de informativos locales. Más tarde, Cristina Saavedra comenzó a presentar "Telexornal Noite", un informativo de madrugada, para luego conducir el espacio de reportajes "Galicia Directo" y presentar el informativo de tarde, "Galicia Noticias". También ha realizado varios reportajes sobre Galicia para el programa World Report de la CNN.

En Junio de 2000, Cristina Saavedra se unió a Antena 3 para presentar "Ahora", programa con el que sigue triunfando las tardes de los sábados.

Volver al principio del epígrafe Volver al principio del artículo Volver al principio

\subsection{Programas de televisión basura de Canal 7}

Canal 7 Televisión no despegó realmente hasta que en la cadena vecina, la autonómica Telemadrid, saltó la sorpresa cuando el director decidió prescindir de uno de los programas de mayor audiencia, "Tómbola", con sus contenidos del corazón llenos de escándalos. Entonces, José Frade fue rápido y consiguió hacerse 
con los derechos para emitirlo en Madrid. Así, tan sólo una semana después de ser retirado de Telemadrid, "Tómbola" ya salía en el aire en Canal 7.

Entonces, las audiencias se dispararon. Canal 7, que hasta entonces contaba con 9000 espectadores en ese horario, pasó a 100.000 superando incluso a las cadenas nacionales, algo impensable en el pasado. Esto trajo consecuencias inmediatas.

Evidentemente, se produjo una auténtica revolución, que provocó aumentos espectaculares en los ingresos publicitarios y esto en poco tiempo repercutió en la programación.

Inmediatamente, empezaron a surgir programas rosas, como "Corazón del Milenio", que vio su audiencia aumentada progresivamente. De este espacio hablaremos más detenidamente.

Podemos decir que esta fue la época dorada de Canal 7, que logró lo que pocas televisiones habían conseguido: emitir una programación continua sin televentas. "Play Music" y "Corazón del Milenio" estaban en pleno apogeo gracias al efecto "Tómbola" (que causaba estragos en las audiencias cada viernes). Como consecuencia de esto, empezaron a ver la luz muchos otros programas: como "E-misión Glamourosa" (una especie de magazine de tarde patrocinado por una importante página web); "Show Store" (un concurso para que la gente demostrara sus habilidades), y por supuesto, mucha telebasura con programas como "Vida Perra" (realmente, se trataba de un espacio de zapping con presentadores); y "Mentiras Peligrosas" (presentado por Leticia Savater y del que hablaremos seguidamente.

\section{$\underline{\text { TÓMBOLA }}$}


Lo más destacado de la historia de este programa fue su cese de emisión en la autonómica Telemadrid.

Pero no hay que permitir que el árbol impida ver el bosque. La muerte de Tómbola no significa el fin de la telebasura. En todo caso, cae su paradigma de los últimos años. Se hace necesario un cambio profundo en los objetivos de programación de las televisiones públicas.

Por otra parte, la supresión de Tómbola en TeleMadrid va a ocasionar, sin duda, una batalla económico-legal en lo relativo al cumplimiento de contratos entre la productora del programa, Producciones 52, y las televisiones que hasta hoy han compartido su emisión. En relación con esta cuestión, llamamos a todas las partes implicadas a negociar una salida limpia y legal, con luz y taquígrafos.

Este programa presenta a una serie de famosos que se enfrentan a un grupo de periodistas del corazón, en diálogos cargados de espectacularidad, en donde no resultan extraños los insultos, las vejaciones, los golpes e incluso las demandas judiciales.

El presentador es Chimo Rovira, un personaje antes desconocido que presenta otro programa concurso por las mañanas en TM3.

Los periodistas fijos que participan en la tertulia son:

- Jesús Mariñas

- Karmele Marchante

- Antonio Herrera

- Lydia Lozano 
La mayoría de los periodistas han sufrido alguna agresión por parte de los invitados durante el programa y también han sido demandados varias veces.

Los entrevistados suelen ser gente de la categoría de Rocío Carrasco, Antonio David Flores, Ricardo Bofill y otros.

El programa se emite en Canal 9 de Valencia a las 21:40 horas el jueves. También lo emite Tele Asturias a las 21:00, y todas las Autonómicas, menos Madrid.

Canal 7 emite Tómbola los viernes noche y lo repone las noches de domingo.

\section{CORAZÓN DEL MILENIO}

Programa que empezó siendo dirigido y presentado por Carlos Ferrando. Después, cambió su decorado y su presentador, que fue durante un tiempo Sergio Alis. Actualmente, Carlos Ferrando vuelve a estar al frente del programa y además, lo dirige. Algunos colaboradores de importancia son Carmen Hornillos o Pepa Jiménez.

Su contenido es parecido al resto de los programas que emiten noticias del corazón. Se emiten vídeos sobre la vida privada de personajes populares que son posteriormente comentados y criticados por los presentadores y colaboradores del programa.

Este espacio se emite de lunes a jueves de 22.00 a 00.00 horas, es decir, durante el período de Prime-Time.

Lo que más atrae de este programa es su presentador, que es conocido por aparecer en otros programas como "Crónicas Marcianas" o "Como la vida". Antes de dedicarse al mundo del corazón, trabajó como jefe de prensa de personas como Almodóvar y Ana Belén. Posteriormente, escribió en revistas como Fotogramas y Diario 16. 


\section{MENTIRAS PELIGROSAS}

Presentado por Leticia Sabater. Se ha hecho muy popular en la televisión actual. Es un "reality show" que imita a los programas sudamericanos, en los que una serie de personas discuten un problema familiar en directo y en presencia de un público. En este caso, los invitados son actores que representan un show previamente preparado. No faltan los golpes, insultos, vídeos falsos y violencia. Se emite por la tarde.

La presentadora de este programa es una de las causas de su creciente éxito. Leticia Sabater comenzó en el programa de Jesús Hermida, y más tarde presentaría programas infantiles como "No te lo pierdas", "Con mucha marcha" o "A mediodía, alegría".

\section{SHOW STORE}

Programa que se emite durante el fin de semana. Está presentado por Malena Gracia, y consiste en un programa donde se buscan artistas nuevos de todo tipo a los que se les premia con 20 euros por actuación.

\section{TU SEGUNDA LUNA DE MIEL}

Reality show también presentado por Leticia Savater, en el que una serie de personas de edad avanzada acuden a la televisión para buscar pareja, y a los que se les regala un viaje a Canarias y un tostador de pan. El público suele ser el mismo que aparece en el programa "Mentiras Peligrosas".

\section{$\underline{\text { VIDA PERRA }}$}


Es un programa de zapping clásico que emite, por cadenas, los minutos más curiosos de la televisión ese día. Está considerado también telebasura, pero quizá en un menor grado que el resto de los programas.

\section{EL SHOW DE CRISTINA}

Programa de origen sudamericano que puede compararse con un reality show, en el que una serie de personas viene a contar al programa sus problemas personales y a solucionarlos en directo, por lo que la espectacularidad está garantizada. Es muy similar a "Mentiras Peligrosas".

\section{Antecedentes}

El origen de este tipo de televisión tiene sus raíces en la radio estadounidense. Después de la II Guerra Mundial, algunos programas comenzaron a recibir llamadas de los oyentes que enviaban saludos a sus familiares y amigos, y que acabaron contando sus tragedias amorosas, laborales o existenciales. Veinte años después, la televisión adoptó este formato y se llenó de vídeos caseros enviados por la propia audiencia que mostraban situaciones más bien ridículas ocurridas a personas normales. Este género de cámara oculta cosechó un rotundo éxito durante los años sesenta y setenta.

Ya en los ochenta surge, también en Estados Unidos, el fenómeno de los "talk shows", donde los invitados hacían públicos sus problemas e incluso podían llegar a las manos ante la mirada atónita de los televidentes. Y su secuela fueron los "reality shows", donde el público se convierte en espectador de la vida y miserias de una serie de personajes que previamente han accedido a destapar sus intimidades ante las cámaras. 


\subsection{Historia de la telebasura en España}

Fue en los noventa cuando empiezan a entrar en las parrillas de programación los denominados reality shows, programas que por primera vez mostraban en España las miserias de ciudadanos anónimos para nutrir a millones de espectadores. Nutrir una curiosidad morbosa, algo inherente al propio ser humano, pero que estos programas ofertaron sin ningún tapujo ni pudor. Cada día se esmeraban más en elaborar una cuidada y minuciosa puesta en escena; los periodistas de la época interrogaban a sus invitados mientras los distintos planos y la música ambiente acentuaban el dramatismo de lo contado.

La gota que colmó el vaso y que desató el fenómeno televisivo actual fue el denominado caso de "las niñas de Alcásser". Todos los espacios televisivos dedicaban gran parte de su contenido al caso hasta que el día que aparecieron los tres cadáveres de las adolescentes muertas, en el que se convirtió en un show. Ese mismo día, los dos canales más fuertes del momento, Televisión Española y Antena 3, contraprogramaron un especial abordando el trágico desenlace. No sólo eso, Antena 3 improvisó un plato en un salón del pueblo para que los ejecutivos de la cadena y Nieves Herrero tocasen su techo profesional. Como invitados los familiares de las tres víctimas, abatidos y sin capacidad de reacción ante el tremendo golpe que les acababa de dar la vida. Uno de los momentos álgidos de la noche se vive cuando entra en escena la periodista Olga Viza anunciando la detención de los presuntos sospechosos. Al instante, el público formado por la gente del pueblo, vitoreaba proclamas a favor de la pena de muerte, muy al estilo de aquellos ajusticiamientos populares de antaño, independientemente de si realmente eran los autores materiales del crimen (más tarde se vio que quien fue apresado en un primer momento fue un hermano de Antonio Anglés). 
Esta es la primera ocasión en que se traficó y se comercializó con el sufrimiento de las personas (conste que anteriormente también ocurrió algo similar con la muerte del torero Francisco Rivera). Esa noche, la fascinación que podía despertar actos repugnantes par nuestra conciencia se transformó en una curiosidad morbosa por deleitarse ante las tragedias de los otros.

A partir de entonces ya no nos extrañaba ver a periodistas revoloteando alrededor de la carroña; tras un atentado terrorista, muchos reporteros aguardaban a los familiares de la víctima en los portales de sus viviendas para captar la mejor instantánea o la más desgarradora de las declaraciones. Sin ir más lejos, la primera noticia que tuvo el padre de Miguel Ángel Blanco acerca del secuestro de su hijo fue "gracias" a los periodistas que le abordaron a la puerta de su casa.

Pero la gente quería más, y la televisión es un mundo que funciona al ritmo de la actualidad, por lo que había que renovar los contenidos.

El nuevo filón se encontraba en el mundo rosa. El glamour de los famosos, sus excentricidades $\mathrm{y}$, sobre todo, la posibilidad de adentrarse en sus intimidades y ver que no son tan distintos de nosotros generó una nueva fiebre mediática.

El mundo del corazón empezó poco a poco a ocupar las sobremesas en las parrillas de programación, una especie de avanzadilla para lo que sería el ataque definitivo. Junto a ello, las tardes se llenaron de magazines en donde las confesiones de maltratos, engaños amorosos u orientaciones sexuales circunscribían la televisión a un público concreto.

El golpe de efecto lo dio el canal autonómico valenciano, Canal 9, con Tómbola, algo así como el tercer grado del famoseo. Lo peor de todo era la pretensión, aún latente, de convertir esos debates en asuntos de interés nacional, mediante la constante 
reivindicación por parte de los periodistas de su papel en el mundo de la información.

A Tómbola le siguieron, cómo no, infinidad de imitadores a lo largo y ancho del panorama nacional, ya no sólo en televisión, sino en prensa escrita. Ello provocó que en algunas cámaras autonómicas se debatiera acerca de la telebasura. En la Comunidad de Madrid, la por entonces socialista Cristina Almeida reprochaba al también por aquel entonces presidente de la Comunidad Alberto Ruiz Gallardón, la proliferación de estos espacios en la cadena pública Telemadrid. El popular replicó a ésta si la telebasura a la que se refería ella eran los programas a los que acudía habitualmente como invitada (citando cadena, día y hora de emisión).

A partir de entonces se abrió la veda. Como si hubiesen firmado un cheque en blanco, los famosos eran perseguidos día y noche. Lo cierto es que la Constitución alude a este fenómeno. De esta forma aquellas personas que por su situación personal o laboral tengan una relevancia de cara al público tienen que soportar esta pequeña carga. Una carga que supone la pérdida del anonimato que todos los demás ciudadanos aún preservamos, pero ni mucho menos el acoso que sufren la mayor parte del tiempo.

El siguiente paso en la "evolución" recuerda mucho a la película de Peter Weir "El show de Truman". En ella, Jim Carrey interpreta a un hombre cuya vida es una ficción televisiva que bate récords de audiencia. Tenemos pues a un hombre concebido por la televisión y cuya progresión como persona está controlada por el guionista y realizador del programa.

Hace unos tres años, la productora Globomedia y Tele 5 lanzaban un programa televisivo a modo de ensayo sociológico: Gran Hermano. De resonancias orwellianas, Gran Hermano consiste en grabar veinticuatro horas al día la convivencia de varias 
personas dentro de una casa, poniéndoles de vez en cuando pruebas para conseguir alimentos o vicios.

En poco tiempo, junto a los rostros que asociábamos con este mundillo se sumaron el de otros totalmente desconocidos, llegando a monopolizar los medios de comunicación de tal forma que sus vidas eran desmenuzadas paralelamente en las distintas cadenas. De esta forma, incluso la vida de completos desconocidos eran (y lo son) objeto de adoración.

Éste es el punto en el que nos encontramos ahora. Ya no nos extrañamos de que secretarias o chóferes hagan públicos los devaneos de aquellos a quienes sirvieron en alguna ocasión, constantemente y en cualquier momento. Todo porque hay un público demandante de este tipo de emociones, enganchado al tráfico sentimental. Hace años eran los toros, después vino el fútbol, y ahora, el nuevo ungüento para calmar a las masas y cegarlas ante los verdaderos problemas de la realidad.

Pocas veces el libre mercado de Adam Smith ha funcionado de una manera tan exitosa.

Resulta paradójico cómo hace más de quince años dos canales de televisión ofrecían una amplia oferta para todos los públicos. Ahora en 2003, con seis canales mediáticos "oficiales" nos encontramos con una televisión monotemática y clasista. La única alternativa apta para todos los públicos (pero no para todos los bolsillos) se encuentra en la plataforma digital.

La vida es una Tómbola... 